\title{
A PERCEPÇÃO DE PAIS SOBRE PROJETO DE EXTENSÃO UNIVERSITÁRIA EM ESCOLA AMAZÔNICA
}

Thais Cristina Flexa Souza', Jacira Nunes Carvalho²

Objetivo: Identificar as percepções de pais sobre as atividades do projeto de extensão realizada pelo profissional de saúde no âmbito escolar. Metodologia: Trata-se de um estudo do tipo descritivo com abordagem qualitativa realizado com 15 pais e/ou responsáveis em uma escola municipal em Belém, Pará, Brasil. Esta pesquisa foi oriunda do projeto de extensão "A ludicidade como ferramenta para promoção da saúde de crianças e adolescentes no espaço escolar" que ocorreu de janeiro de 2014 até fevereiro de 2017 com apoio da Pró-Reitoria de Extensão/UFPA. Resultados: As categorias encontradas foram: a necessidade e a importância de projeto de extensão na comunidade; elencando os temas para atividades de educação em saúde; reconhecendo a vulnerabilidade social em que vivem. Conclusões: Foi possível afirmar que o projeto de extensão universitário em saúde dentro do ambiente escolar é uma prática eficaz para ensinar e divulgar boas práticas para promoção da saúde.

Descritores: Enfermagem familiar; Saúde Escolar; Enfermagem.

\section{THE PERCEPTION OF PARENTS ON THE PROJECT OF UNIVERSITY EXTENSION IN AMAZON SCHOOL}

Objective: Identify the perceptions of parents about the activities of the extension project realized by the health professional in the school context. Methodology: This is a descriptive study with a qualitative approach realized with 15 parents and / or tutors in a municipal school in Belém, Pará, Brazil. This research originated from the extension project "Ludicity as a tool for the health promotion children and adolescents in school space", which occured from January 2014 until February 2017 with the support of the Pro-Rectory of Extension/ UFPA. Results: The categories found were: the need and importance of extension project in the community; listing the themes for health education activities; recognizing the social vulnerability in which they live. Conclusions: It was possible to affirm that the project of university extension in health within the school environment is an effective practice to teach and to divulge good practices for health promotion.

Descriptors: Family Nursing; School Health; Nursing.

\section{LA PERCEPCIÓN DE PADRES SOBRE EL PROYECTO DE EXTENSIÓN UNIVERSITARIA EN ESCUELAAMAZÔNICA}

Objetivo: Identificar las percepciones de los padres sobre las actividades del proyecto de extensión ejercidas por profesionales de la salud en las escuelas. Metodología: Se trata de un estudio descriptivo con un enfoque cualitativo realizado con 15 padres y/o tutores en una escuela municipal en Belém, Pará, Brasil. Esta investigación se deriva del proyecto de extensión "El lúdico como herramienta para la promoción para la salud de los niños y adolescentes en espacio escolar", que ocurrió entre enero de 2014 hasta febrero de 2017 con el apoyo de Pro-Rectoría de Extensión / UFPA. Resultados: Las categorías fueron: reforzando la necesidad y la importancia del proyecto de extensión en la comunidad; listando los temas para actividades de educación para la salud; el reconocimiento de la vulnerabilidad social en el que viven. Conclusiones: Fue posible afirmar que el proyecto de extensión universitaria en salud dentro del espacio escolar es una práctica efectiva para enseñar y difundir las buenas prácticas para la promoción de la salud.

Descriptores: Enfermería de la familia; Salud Escolar; Enfermería. 


\section{INTRODUÇÃO}

Historicamente, os profissionais de saúde sempre estiveram próximos às famílias e as enfermeiras prestavam cuidados nos contextos diversos. Existem evidências desde Florence Nightingale, que os membros das famílias eram incluídos nos cuidados de saúde de seus entes nas práticas de cuidados dirigidas as famílias ${ }^{(1)}$.

A família deve ser o foco prioritário da atenção primária para possibilitar espaços para educação em saúde, extinguindo o olhar individualizado do cuidado a esta estrutura. Assim, é importante o grupo familiar estar contextualizado nas múltiplas dimensões do processo saúde-doença ${ }^{(2)}$.

Semelhantemente a família, outro ambiente social é a escola, esta tem como missão desenvolver processos de ensino- aprendizagem, formação dos estudantes e construção da cidadania. Dessa maneira, a escola é o local onde os programas de educação em saúde podem ter maior e melhor repercussão abordando e influenciando o educando nas melhores fases de sua vida: infância e adolescência ${ }^{(3)}$.

Contudo é por meio da extensão universitária que a Universidade interage com a comunidade gerando uma troca de conhecimentos com a comunidade, absorvendo seus valores e cultura. A extensão é uma importante ferramenta para a formação de profissionais, visto que aproxima o saber científico de realidades múltiplas desenvolvendo nestes as habilidades necessárias e os aspectos humanísticos e éticos tão importantes na vida ${ }^{(4)}$. Nesta perspectiva, o objetivo do estudo é identificar as percepções de pais sobre as atividades do projeto de extensão realizada pelo profissional de saúde no âmbito escolar.

\section{METODOLOGIA}

Trata-se de um estudo do tipo descritivo com abordagem qualitativa. A pesquisa de abordagem qualitativa tem caráter subjetivo. Este coleta e analisa sistematicamente materiais narrativos ${ }^{(5)}$. O estudo foi realizado com 15 pais e/ou responsáveis em escola municipal no bairro da Terra Firme, Belém, Pará, Brasil.

Esta pesquisa foi oriunda do projeto de extensão " $A$ ludicidade como ferramenta para promoção de crianças e adolescentes no espaço escolar" que ocorreu 01/2014 até 02/2017 com apoio da Pró- Reitoria de Extensão/UFPA, este visou contribuir com a promoção da saúde de crianças e adolescentes na escola com a utilização de estratégias lúdicas. Foram incluidos pais/responsáveis maiores de idade, de ambos os sexos, com filhos matriculados na escola que ocorreu a pesquisa e foram excluidos os pais com algum problema físico, mental ou de comunicação que impossibilitasse a entrevista. Ao aceitar participar, os objetos da pesquisa, a forma de coleta de dados e o compromisso do pesquisador com os dados da pesquisa foram esclarecidos e ao fim solicitava-se que assinassem o TCLE (Termo de Consentimento Livre e Esclarecido).

A coleta de dados foi realizada no horário de entrada e saída da escola. As entrevistas foram gravadas e respondiam a seguinte pergunta: Como um projeto de extensão Universitário pode estar contribuindo para o conhecimento sobre saúde no âmbito escolar?A entrevista aberta é utilizada quando o pesquisador deseja obter o maior número possivel de informações e detalhamento do assunto em questão. Os dados foram analisados à luz da análise temática de acordo com Minayo ${ }^{(6)}$. A pesquisa tem aprovação ética n으 1.578.008 do Instituto de Ciências da Saúde/UFPA.

\section{RESULTADOS}

Foram entrevistados 15 pais/responsáveis, todos do sexo feminino entre 27 e 62 anos com escolaridade desde ensino superior completo a fundamental incompleto. Para assegurar o anonimato dos participantes, utilizou-se nome de frutas. As categorias encontradas foram três: necessidade e a importância de projeto de extensão na comunidade; elencando os temas para atividades de educação em saúde; reconhecendo a vulnerabilidade social em que vivem.

\section{Necessidade e a importância de projeto de extensão na comunidade}

Estar na escola, cuidar de crianças e adolescentes não é algo que seja encorajador na academia dos cursos da área da saúde, dada as especificidades no trato com esta clientela. Estas atitudes geralmente partem de iniciativas extensionistas, executadas por alguns que percebem a necessidade deste aprendizado sobre o cuidado a saúde desde a infância. Assim, no percurso da vida todos precisam de auxilio, e com os pais e ou responsáveis esta premissa também é verdadeira, eles precisam de orientações para si e o para o grupo familiar.

A participação dos escolares nas atividades desenvolvidas pelos projetos de extensão contribuiu para a implementação das mudanças não só em âmbito escolar, mas também no nível individual com a mudança de comportamento e atitude. De acordo com as falas abaixo, compreendemos que alunos e pais valorizam a ação de projetos de extensão no ambiente escolar.

Com certeza. Ele fala o que acontece com ele e procura me ajudar, ele procura corrigir o que tá errado [...] (Açai)

Com certeza. Ela repassa [...] dependendo da forma que às vezes a mãe ensina em casa e acriança vê um profissional na escola ensina a criança de outra maneira, a criança vai ver o certo, ela vai saber que lá em casa, ela tá aprendendo errado [...] (Acerola)

26 I Enferm. Foco 2018; 9 (3): 25-29 


\section{Elencando os temas para as atividades de educação em saúde}

Ao longo das falas, pode-se notar que os pais tem percepção da importância do projeto no âmbito da escola como uma atividade de fortalecimento para o aprendizado dos alunos de maneira geral e especificamente no concernente os aspectos do cuidado da vida e saúde de seus filhos. Os pais elencam maneiras e temas a serem discutidos com crianças e adolescentes que consideram pertinentes para esta fase do ciclo vital. Dentre eles, a educação sexual foi um dos temas que os pais sugeriram como uma temática atual e de suma importância para o aprendizado de como evitar doenças sexualmente transmissíveis e gravidez indesejada.

[...] Adolescente que não tem uma experiência de vida e cai nessa armadilha no mundo de hoje. São as AIDS, essas doenças aí [...] É uma doença que não tem cura ainda.

[...] Educação sexual pros jovens aprenderem, porque hoje em dia tem um monte de doenças aparecendo, aí tem que adverter, tem que fazer essas alertações, fazendo palestras pros jovens. (Taperebá)

A higiene bucal foi outro tema que os pais afirmaram ser necessário de ser abordado desde cedo nas escolas. Assim como, a possibilidade dos pais serem orientados e recebam esclarecimentos dos odontólogos sobre as formas corretas de cuidados orais para assim acompanharem e ajudarem os filhos na correta escovação dos dentes, evitando desta forma doenças bucais como cáries e gengivites e até mesmo a perda de dentes ainda na fase da adolescência, fatos estes muito comuns nas periferias das grandes cidades nas populações menos favorecidas.

[...] Deveriam abordar muito sobre higiene bucal, né? Ensinarem as crianças a escovar os dentes. Que muitas crianças eu vejo assim, que não tem esse hábito [...] (Maracujá)

[...] Olha, como eu te falei, parte de odonto [...] (Acerola)

Para os pais a higiene corporal é considerada outro tema essencial para abordar em atividades de educação em saúde, pois a higiene pessoal e ambiental correta diminui o risco de doenças, refletindo na qualidade de vida. Na escola, os hábitos de higiene devem ser reforçados considerando que neste ambiente as crianças fazem refeições, se socializam no contato com os colegas e professores, usam banheiros e lavabos na manutenção do cuidado a saúde, estes hábitos ensinados na infância se cristalizam como uma conduta adequada para a vida quanto antes ensinados as crianças melhor será o desenvolvimento deste hábito.
[...] Questão de higiene a mais que serve pra todo mundo [...] (Uxi)

[...] Tem que explicar que eles ao podem ta pegando em terra, em areia, porque isso, nessa água parada, tem que explicar pra eles que isso faz mal [...] Como é que deve ser eu não deve ta na sujeira [...] (Graviola)

Pais e responsáveis se preocupam e ficam incomodados diante de comportamentos e atitudes inadequadas e até mesmo violenta de alguns alunos, durante a entrevista relataram sentir falta de uma assistência psicológica para os alunos por observarem o comportamento destes na escola, marcado por má conduta, agitação e desobediência. Entendem que estes problemas, não devem ser somente de responsabilidade da escola, mas também da família.

[...] Psicologia, pra ta ajudando os adolescentes, crianças mesmo, porque tem muitas crianças aqui com problemas [...] (Acerola)

[...] Pra eles se comportarem mais, porque eles são muito agitados, quase não obedecem [...] (Manga)

[...] Tem muita criança que são muito mal-educadas e eu acho sim que deveria ter uma pessoa pra orientar mais eles [...] São umas criança muito agitada [...] Precisa de um psicólogo aqui na escola pra elencar essas crianças assim [...] (Muruci)

Outro tema sugerido foi sobre lavagem das mãos, que é uma técnica importante para evitar a disseminação de doenças por bactérias e por isso deve ser ensinada por educadores como um mecanismo de prevenção. Por conseguinte, tem como benefícios: diminuir o número de microorganismos, eliminar sujidades e proteger a própria saúde. Para as crianças, a melhor hora que deve ser reforçada esta prática é antes das refeições e contato com alimentos.

[...] Vocês que são da saúde, vocês podem explicar pra eles, como deve ser, como é que deve antes de almoçar, jantar, se alimentar, tem que lavar as mãos bem lavadinha [...] (Graviola) [...] A limpeza das mão antes de comer, antes de pegar no alimento [...] (Banana)

A alimentação é outro tema que deve ser explorado para combater a desnutrição e obesidade, desta última os indices são crescentes no Brasil. Além disso, abordar esta temática na escola incentiva os alunos à prática alimentar saudável. Uma alimentação saudável proporciona qualidade de vida, pois faz o corpo funcionar adequadamente e, além disso, é uma das melhores formas de prevenção para qualquer doença. Outro ponto tocado pelos pais foi à questão da higiene com a manipulação de alimentos. A higienização adequada dos alimentos é importante para evitar a 
contaminação química, física ou microbiológica. As pessoas que ingerem alimentos contaminados podem adoecer e em casos mais graves, irem a óbito.

[...] Eu acho assim, sobre alimentação [...] meu filho, por exemplo, não gosta da merenda da escola [...] (Cupuaçú)

[...] Eles vão e compram lá fora, e quando é depois, eles estão com dor na barriga, se sentindo mal [...] Como lidar com o alimento, de ingerir, seria muito bom. (Banana)

Reconhecendo a vulnerabilidade social em que vivem

Os pais reconhecem que residem em um local onde o acesso às drogas, criminalidade é muito recorrente e nestes locais há uma necessidade da implantação de projetos sociais e projetos de extensão por meio de universidades para tratar temas pertinentes à saúde, educação e segurança. E eles vêem os projetos no geral como uma ferramenta de transformação social da realidade em que eles estão inseridos. Não sendo esta uma realidade restrita a este bairro e a esta população, pois entendemos que em grandes centros urbanos há sempre uma área periférica onde residem pessoas de baixo poder aquisitivo e nestes bolsões estão sempre presentes a droga, a prostituição e a violência.

[...]Aqui onde moramos, num bairro vulnerável, a questão de drogas, sobre o risco que tem as drogas, as más influências[...] Eles não escutam com que os pais falam dentro da sua casa, eles escutam mais de fora, dão mais atenção fora do que dentro (Pupunha)

\section{DISCUSSÃO}

A educação em saúde é uma estratégia adotada por profissionais de saúde que deve ser capaz de promover mudanças de comportamentos, nas práticas diárias e nas atitudes de cada individuo, conduzindo em cadeia a transformação social de uma comunidade. Neste sentido esta contribui para que as pessoas adquiram autonomia para identificar e utilizar meios para preservar e melhorar a sua vida. A criança é uma disseminadora de conhecimento, ela vivencia, brinca, interage e aprende com as trocas, levando suas experiências para sua casa ${ }^{(7)}$.

A escola tem sido um espaço de intervenção sobre a sexualidade adolescente que ultimamente adquiriu uma dimensão de problema social. A intenção de introduzir esse assunto no âmbito escolar torna-se evidente pela inserção da orientação sexual nos Parâmetros Curriculares Nacionais (PCN's) na forma de tema transversal. A atual inclusão da educação sexual na escola é justificada pelo crescimento do número de casos de "gravidez indesejada" e pela disseminação de casos de contaminação pelo HIV ${ }^{(8)}$.
A atenção à saúde bucal deve ser iniciada em idade precoce, tendo como ponto central o enfoque preventivo. Desta maneira, a educação dos pais possui papel fundamental, pois quanto mais precocemente se estabeleçam barreiras preventivas, melhores serão as condições futuras de saúde bucal da criança $a^{(9)}$.

A higiene corporal é um fator preponderante na vida das pessoas, pois eleva a auto-estima, melhora a aparência e previne diversos agravos à saúde como as doenças infecciosas, entre elas: a $\mathrm{HINl}$ e as diversas diarreias e parasitoses $^{(10)}$.

Os problemas de comportamento na infância parecem desafiar a escola e a família para a execução de suas funções educativas, assim como para a criação de propostas de interação entre as mesmas. Nessa interlocução, muitas ações e ideias podem ser congruentes, aproximando e dando continuidade à tarefa educativa da família e da escola; enquanto outras mostram distância, diferenças e descontinuidades ${ }^{(11)}$.

A lavagem das mãos é uma medida eficaz na prevenção e disseminação de doenças além de gerar benefícios extensiveis àqueles envolvidos no cuidado, devendo configurarse como um hábito importante que deve ser estimulado durante a infância ${ }^{(12)}$

A promoção da alimentação saudável na infância estimula a adesão a um bom estilo de vida com um adequado desenvolvimento cognitivo e colabora na prevenção de doenças. Logo, o ambiente escolar é um setor estratégico para a concretização de iniciativas de educação em saúde e conforma-se com o conceito de "Escola Promotora da Saúde". A manipulação adequada dos alimentos também deve ser abordada no ambiente escolar para se evitar doenças gastrointestinais provenientes da falta de higiene (13).

$\mathrm{Na}$ fala dos pais é perceptível que eles têm consciência da vulnerabilidade social em que estão inseridos. A vulnerabilidade social é definida quando os recursos de um grupo social são inadequados para lidar com as oportunidades oferecidas pela sociedade. Essas oportunidades constituem uma forma de ascender a maiores niveis de bem-estar ou diminuir probabilidades de deterioração das condições de vida. Os projetos de extensão realizados pela universidade, na qual esta tem uma política social voltada para ajudar a comunidade, é uma maneira de combater esta vulnerabilidade ${ }^{(14)}$.

\section{CONSIDERAÇÕES FINAIS}

É importante enfatizar que há necessidade de projetos de extensão apoiados pelas universidades em escolas de ensino fundamental e médio, para assim levarem informações de saúde para crianças e adolescentes de forma

28 I Enferm. Foco 2018; 9 (3): 25-29 
lúdica, ou seja, concomitantemente envolvendo o brincar, refletir e aprender. Com este estudo, observou-se os pais elencaram para atividades de educação em saúde foram: educação sexual, comportamento, higiene bucal, higiene corporal, lavagem das mãos e alimentação.

Em algumas falas, percebe-se também que alguns pais sentem que as próprias famílias estão vulneráveis a situações alarmantes, como violência e drogas por residirem em bairros periféricos e o ambiente ser propício a tais condições. Assim, eles vêem no profissional de saúde uma espe- rança de mudança ao realizar atividades de educação em saúde em propor mudanças de perspectivas de jovens para uma vida saudável.

Em suma, foi possivel perceber que os pais são sensiveis e compreendem a importância de atividades de extensão no âmbito da escola e afirmar que o projeto de extensão universitário em saúde no ambiente escolar é uma prática eficaz para ensinar e divulgar boas práticas para promoção da saúde e traz bons resultados tanto para os escolares quanto para a sua família e comunidade.

\section{REFERÊNCIAS}

1. Sl Carvalho FFB. A saúde vai à escola: a promoção da saúde em práticas pedagógicas. Physis [Internet]. 2015 Dez [citado $2017 \mathrm{Ma}$ 29]; 25(4): 1207-1227. Disponivel em: http://dx.doi.org/10.1590/SO10373312015000400009 .

2. Queiroz TA, Carvalho FPB, Simpson CA, Barreto ELF; Fernandes ACL. Family: meaning to the family health strategy professionals. Rev Bras Promoç Saúde [Internet]. 2015Abr[cited 2017 May 29]:28(2):274-280. Avaliablefrom: http://periodicos.unifor.br/RBPS/article/view/3230.

3. Schmitt ACAN, Costenaro RGS, Rangel RF, Ferreira CLL, Lacerda MR. Mudanças no comportamento e desenvolvimento do escolar a partir do cuidado à familia. Rev. bras. enferm. [Internet]. 2013 Out [citado 2017 Mai 29] ; 66(5): 682-687. Disponivel em: http://dx.doi.org/10.1590/ S0034-71672013000500007.

4. Rodrigues ALL, PrataMS, Batalha TSB, Costa CLNA, Passos Neto IF. Contribuições da extensão universitária na sociedade. Cadernos de Graduação - Ciências Humanas e Sociais [Internet]. 2013Mar[citado 2017 Mai 29]; 16:141-148. Disponivel em: https://periodicos.set.edu.br/ index.php/cadernohumanas/article/viewFile/494/254.

5. Pesce L, Abreu CBM. Pesquisa qualitativa: considerações sobre as bases filosóficas e os princípios norteadores. Revista da FAEEBA Educação e Contemporaneidade [Internet]. 2013 Jul./Dez[citado 2017 Mai 29];22 (40): 19-29. Disponivel em: https://www.revistas.uneb.br/index.php/faeeba/article/viewFile/747/520.

6. Minayo MCS. O desafio do conhecimento: pesquisa qualitativa em saúde. 3a ed. São Paulo: Hucitec/Abrasco; 2014.

7. Krug MR, Fernandes RGP, Pedro TPHOI, Soares FAA. Promoção da saúde na escola: um estudo com professores do ensino médio. Scentiaplena [Internet]. 2015 Mai[citado 2017 Mai 29]; 11(5): 1-9. Disponivel em: https://www.scientiaplena.org.br/sp/article/view/2374/1203.

8. Janczura R. Risco ou vulnerabilidade social? Textos \&Contextos [Internet] 2012 Ago./Dez [citado 2017 Mai 29];11(2):301-308. Disponivel em: http://revistaseletronicas.pucrs.br/fo/ojs/index.php/fass/article/ view/12173/8639.

9. Silva DM,Alves MR, SouzaTO, DuarteACS. SexualidadenaAdolescência: Relato de experiência. RevEnferm UFPE online.[Internet] 2013 Mar [citado 2017 Mai 29]; 7(1):820-823. Disponivel em: http://www.revista.ufpe.br/revistaenfermagem/index.php/revista/article/viewFile/3681/pdf_2201.

10. Garbin CAS, Rovida TAS, GarbinAJI, Arcieri RM, Souza NP, Moimaz SAS. Saúde bucal e educação infantil: avaliação do desgaste e do acondicionamento de escovas dentárias utilizadas por pré-escolares. RevOdontol UNESP[Internet] 2012 Mar/Abr[citado 2017 Mai 29]; 41(2): 81-87. Disponivel em: https://repositorio.unesp.br/bitstream/handle/11449/133371/ISSN18 07-2577-2012-41-02-81-87.pdf?sequence=1EisAllowed=y

11. Sarkar M. Personalhygieneamongprimaryschoolchildren living in a slumof Kolkata, India.J PrevMedHyg.[Internet]2013Sep[cited 2017 May 29]:54(3): 153-158.Avaliablefrom: https://www.ncbi.nlm.nih.gov/pmc/ articles/PMC4718376/.

12. Silveira $L M O B$, Wagner A. A interação familia-escola diante dos problemas de comportamento da criança: estudos de caso. Psicol. educ.[Internet]2012Ago[citado 2017 Mai 29];35: 95-119. Disponivel em: http://pepsic.bvsalud.org/scielo.php?script=sci_arttext\&pid=S141469752012000200006

13. Mota EC, Barbosa DA, Silveira BRM, Rabelo TA, Silva NM, Silva PLN, et al.Higienização das mãos: uma avaliação da adesão e da prática dos profissionais de saúde no controle das infecções hospitalares. Rev Epidemiol Control Infect.[Internet]2014 Jan [citado 2017 Mai 29];4(1):12-17.Disponivelem: https://online.unisc.br/seer/index.php/epidemiologia/article/view/4052/3379.

14. Rossetti FX, Stolarski MC, Schmidt ST. Estado nutricional de adolescentes do sudoeste do Paraná, Brasil. Segurança Alimentar e Nutricional [Internet] 2015 Ago[citado 2017 Mai 29]; 21(2):437-447. Disponivel em:https://periodicos.sbu.unicamp.br/ojs/index.php/san/ article/view/8642502/10022 